\title{
Transcriptome survey and expression analysis reveals effects and metabolic pathways of Yuluxiang Pear in response to drought stress
}

\section{Sheng Yang}

Shanxi Agricultural University

\section{Mudan Bai}

Shanxi agricultural university

Guowei Hao

Shanxi Agricultural University

Xiaowei Zhang

Shanxi Agricultural University

\section{Yanping Wang}

Shanxi Agricultural University

Huangping Guo ( $\nabla$ ghping1959@163.com )

Shanxi Agricultural University

\section{Baochun Fu}

Shanxi Agricultural University

\section{Research article}

Keywords: Yuluxiang pear, Drought stress, Transcriptome, Lignin, Plant hormone

Posted Date: August 17th, 2020

DOI: https://doi.org/10.21203/rs.3.rs-47579/v1

License: (9) This work is licensed under a Creative Commons Attribution 4.0 International License. Read Full License 


\section{Abstract}

Background: Pear is one of the most important economic fruits worldwide. The quality and productivity is frequently threatened by drought disaster, but the effects mechanism of drought stress on pear has not been well understood, especially in respond to drought stress at the gene transcription levels.

Results: That showed that drought stress weakened antioxidant systematization and the synthesis of photosynthetic pigment of Yuluxiang Pear leaves, and the reduced light utilization and photosynthetic productivity finally resulted in the inhibited fruit development. The transcriptome from leaves were sequenced and analyzed using Illumina HiSeq 2500 to evaluate the effects of drought stress on the expression of genes in different biosynthetic pathways. Deferentially expressed genes analysis showed that the enzyme genes involved in lignin biosynthesis were up-regulated by drought stress, and the promoted lignification process may be beneficial to decrease the transpiration rate and increase water use efficiency of Yuluxiang Pear leaves. The up-regulated malate dehydrogenase and adenosylmethionine decarboxylase were also observed in drought stress groups, and the activated soluble sugar biosynthesis could be helpful to promote osmotic regulation and increase antioxidant capacity to enhance drought resistance of leaves. Drought stress increased the expression of enzyme genes related with hormones biosynthesis including ethylene, abscisic acid, and gibberellin, suggesting promoted cell proliferation and slowed young leaves growth.

Conclusions: Present study reveals that drought stress severely decrease photosynthetic productivity to negatively affect fruit development, and the inhibited photosynthesis could be closely related with drought-induced lignification and hormones promoting leaf abscission.

\section{Background}

Pear is one of the most widely grown fruit species worldwide, and currently ranks fifth in total world fruits production only after grapes, oranges, bananas and apples. More than 25 million tons pear were produced worldwide in 2017 [1, 2], and nearly three-quarters (about 18.75 million tons) of that was contributed by China. However, the unpredictable reduction of pear yield is an urgent problem. In the pear origin of northern China, the pear production is traditionally correlated with weather conditions, and is used to be passively affected by adverse weather, such as drought disaster [3, 4]. The drought disaster is a uncertainty and dangerous climatic hazard threatening fruits production in many areas of the world [57].

Plants is inseparable from water, and too little water would negatively affect the normal physiological function, such as photosynthesis. Studies found that water deficiency was second only to the shortage of illumination causing decreased photosynthetic rate $[8,9]$. And, water deficiency leaded to the increased temperature of plant leaves promoting transpiration, and the contradiction between supply of water and demand of plant body resulted in the decreased photosynthetic rate. Maes et al. [10] found that the water potential, relative water content, leaf area, stomatal conductance of fruit seedlings leaves under drought 
stress was reduced, which finally caused the decline of leaf photosynthetic rate. The decline of leaf photosynthetic rate under severe water stress was much more serious than that under mild water stress. Decreased stomatal conductance caused by water stress could inhibit the entry of carbon dioxide from the external environment into leaves, and increased resistance of mesophyll cells, and decreased carboxylase activity, which ultimately leads to a decrease in photosynthetic rate [11].

The effects of drought stress on plant growth and development has been studied, but the regulation mechanism at the molecular level is less reported. Sequencing of the pear genome provides a possibility for gene prediction and annotation. Yuluxiang pear, one the most widely fruit in China because of its economic value and excellent resistance and tolerance to unfavorable environmental factors, were chosen in our present study. Drought stress treatment group and normal watering control group were set up, respectively, and transcriptome sequencing and analysis techniques were used to reveal the regulation mechanism of drought stress on the growth and development of Yuluxiang Pear at the transcriptome level. The knowledge about the expression patterns of genes in Yuluxiang Pear under drought stress may be helpful in narrowing down on candidate genes, which can be used as a foundation for improving the quality of Yuluxiang Pear during cultivation in breeding in the future.

\section{Results}

\section{Effects of drought stress on multiple indicators of Yuluxiang Pear}

Fruit quality analysis of Yuluxiang Pear showed that drought stress significantly decreased the content of fruit soluble solids which led to down-regulated fruit weight (Table 1), indicating that drought stress negatively inhibited the nutrients accumulation and fruit development. The nutrients accumulation in fruit depends on the transportation from photosynthesis products in leaves, and blocked transportation or inhibited photosynthesis may cause the decreased fruit soluble solids. The detection of photosynthetic characteristics in leaves found that values of $\mathrm{Pn}, \mathrm{Tr}, \mathrm{Ci}$, and $\mathrm{Gs}$ in drought stress groups were lower compared to that of control groups (Table 2), and the photosynthesis process in leaves was seriously blocked by drought stress. Further research found that the content of photosynthetic pigment including chlorophyll a, chlorophyll b, and carotenoid was down-regulated in leaves of drought stress groups (Table 3 ), indicating a weaken light utilization and photosynthetic productivity. The damaged photosynthetic pigment was mostly caused by oxidative stress, which was confirmed by the increased malondialdehyde. The reduced activity of SOD, POD, and CAT in drought stress groups was observed (Table 4), suggesting a weaken antioxidant systematization and enhanced oxidative stress under drought stress. Moreover, the content of soluble protein and proline in leaves of drought stress groups decreased (Table 5). Lower concentration of cell solution could cause the down-regulation of osmotic potential, and negatively affected the ability of cell to absorb or retain water, leading to more serious damage on Yuluxiang Pear leaves.

\section{"Insert Table 1-5 here"}

Functional annotation of transcriptome sequencing based on Public Databases 
As shown in Table 1, there were 204157258 and 209344612 clean reads including 30827745958 , 31611036412 nucleotides in control groups and drought stress groups, respectively (Table 5). The sequencing data usually contains some low-quality reads with connectors which would cause great interference to the subsequent information analysis, therefor it was necessary to further filter the sequencing data, and 189653068 and 194811350 reads were finally obtained after splice and redundancy check (Table 6). For annotation, distinct gene sequences were searched using BLASTX against the GO, KEGG, EC, and eggNOG databases (Table 7).

\section{"Insert Table 6-8here"}

\section{Gene Ontology (GO) Classification}

DEGs were determined at a threshold of $\mid$ log2 Fold Changel $\geq 1$ with $p$ value $\leq 0.05$. Based on sequence homology, transcripts were assigned to GO classes to classify the functions of the Yuluxiang Pear genes. The assigned GO terms were summarized into the three main $\mathrm{GO}$ categories, biological process (BP), cellular component (CC), and molecular function (MF), and then into 30 main functional categories (Figure 1). According to $\mathrm{GO}$ annotation and functional enrichment analysis of deferentially expressed genes (DEGs), biological process comprised 5193 (45.09\%) GO annotations and was the largest cluster, followed by molecular function 4035 (35.04\%), and cellular component 2288 (19.87\%). And, there were 747, 1929, 2811 up-regulated genes and 1541, 2106, 2382 down-regulated genes, respectively, were observed (Table 9).

\section{"Insert Table 9 and Figure 1 here"}

\section{KEGG Classification}

The metabolic pathway $P \leq 0.05$ was defined as the KEGG pathway with significant enrichment of DEGs by searching KEGG database. $61 \mathrm{DEGs}$ involved in biosynthesis of secondary metabolites were found (shown in Table 10). Among them, 17, 12, 8, 6, 6, 5, 4, and 3 DEGs were annotated from phenylpropanoid biosynthesis pathway, cysteine and methionine metabolism pathway, flavonoid biosynthesis pathway, diterpenoid biosynthesis pathway, carotenoid biosynthesis pathway, monoterpenoid biosynthesis pathway, sesquiterpenoid and triterpenoid biosynthesis pathway and brassinosteroid biosynthesis pathway, respectively.

\section{"Insert Table 10 here"}

\section{Effects of drought stress on the expression of genes related to secondary metabolism in Yuluxiang pear leaves}

According to the analysis of DEGs in the transcriptome of Yuluxiang pear leaves, drought stress could increase the expression of some key enzyme genes in the biosynthesis pathway of phenylpropanoid, cysteine, methionine, flavonoid, diterpenoid and other effective components in Yuluxiang pear leaves (Table 11), including the rate limiting enzyme of lignin biosynthesis (peroxidase, caffeic acid 3-0- 
methyltransferase, shikimate 0-hydroxycinnamoyltransferase, cinnamyl-alcohol dehydrogenase, cinnamoyl-CoA reductase, ferulate-5-hydroxylase), the rate limiting enzyme of terpenoids biosynthesis (Neomenthol dehydrogenase,(3S)-linalool synthase, Lupeol synthase 2), the rate limiting enzymes of flavonoid biosynthesis (Chalcone synthase), the rate limiting enzymes of methionine biosynthesis (Methionine-gamma-lyase), the rate limiting enzymes of cysteine biosynthesis (cysteine synthase). These up-regulated genes indicated that the accumulation of lignin, terpenoids and flavonoids in Yuluxiang pear under drought stress were promoted, and the pathways of carbon fixation and polyamines biosynthesis was also enhanced.

\section{"Insert Table 11 here"}

\section{Effects of drought stress on the expression of plant hormone related genes in Yuluxiang pear leaves}

Plant hormone is an important factor regulating plant growth and development and adaptation to adversity. The KEGG pathway analysis of DEGs in transcriptome of Yuluxiang pear leaves showed the regulation of drought stress on ethylene, abscisic acid, gibberellin, brassinolide and other plant hormone biosynthesis and / or signal transduction pathways (Table 12). The analysis of transcriptome data showed that drought stress increased the expression of key enzyme genes of ethylene biosynthesis (1aminocyclopropane-1-carboxylic acid synthetase, and aminocyclopropanecarboxylate oxidase) and abscisic acid biosynthesis (9-cis-epoxycarotenoid dioxygenase). More ethylene and abscisic acid could induce leaf abscission, and reduce water loss under drought stress. Moreover, up-regulated expression of enzyme genes involved in gibberellins biosynthesis (gibberellin 2beta-dioxygenase), and inhibiting the activity of brassinolide (PHYB activation tagged suppressor 1 ) were also observed under drought stress.

\section{"Insert Table 12 here"}

\section{Discussion}

Drought stress, known as water deficit stress, is the most common environmental stress with many characteristics including high frequency, wide distribution, long duration and great harm. Drought stress negatively affects normal physiological function and development of plants, and seriously threaten agricultural production. Present study found that drought stress reduced the content of fruit soluble solids, and caused seriously impairments on the fruit quality of Yuluxiang Pear. The drought stress also decreased $\mathrm{Pn}, \mathrm{Tr}, \mathrm{Ci}$, and $\mathrm{Gs}$, the blocked the photosynthesis process was the main cause resulting in the reduced nutrients accumulation in fruit. During the long-term evolution process, plants form unique growth habits, and physiological characteristics in respond to drought stress [12] and the slowed photosynthesis process in Yuluxiang Pear leaves under drought stress could effectively reduce water loss to adapt to drought conditions. To find and reveal the molecular mechanism of plant adaptation to drought stress, it is conducive to the cultivation of drought resistant varieties. Studies on the drought resistance mechanism of plants found variety of molecular mechanisms including up-regulating the cell osmotic regulation ability by the induced synthesis of aquaporin and small molecule soluble organic matter, increasing the stability of biomembrane and protein by induced synthesis of LEA protein and 
membrane protein, clearing free radicals by induced antioxidant protection enzyme system under moderate drought stress $[13,14]$. However, we found the decreased soluble protein and proline in leaves of Yuluxiang Pear, and indicated a down-regulated osmotic potential, suggesting that the ability of cell to absorb or retain water was greatly damaged under severe drought stress. The damage was mainly from oxidative stress which was confirmed by the increased malondialdehyde and a weaken antioxidant systematization. The enhanced oxidative stress induced by drought stress also decreased the photosynthetic pigment levels, causing the weaken light utilization and photosynthetic productivity in leaves.

Studies found that drought stress could promote the accumulation of secondary metabolites such as terpenes and flavonoids in plant roots to enhance osmotic regulation and clear free radicals to adapt the drought environment $[15,16]$. Indeed, the analysis of KEGG pathway enrichment of differentially expressed genes in present study showed that drought stress up-regulated the expression of some key enzyme genes involved in terpenoids, flavonoids, methionine, and cysteine biosynthesis pathway, indicating that drought stress induced these substances synthesis to relieve osmotic stress and oxidative stress in leaves of Yuluxiang pear. The osmotic regulation and antioxidant capacity of leaves in drought treated groups was achieved by up-regulated expression of malate dehydrogenase, and enhanced carbon fixation pathways promoted the biosynthesis of soluble sugar. The soluble sugar not only could regulate osmotic stress and relive free radicals, but also provide energy for the basic physiological function of leaves cells by respiration [17]. Moreover, we found that drought stress down-regulated the expression of limiting enzymes of lignin biosynthesis including peroxidase, caffeic acid 3-0-methyltransferase, shikimate 0-hydroxycinnamoyltransferase, cinnamyl-alcohol dehydrogenase, cinnamoyl-CoA reductase, ferulate-5-hydroxylase, and the enhanced lignin biosynthesis indicated that cell wall synthesis was promoted under drought stress to strengthen the water transportation system in leaves .

Plant hormone is an important factor regulating vary of physiological processes including cell division, elongation, differentiation, and plant germination, rooting, flowering, fruiting, sex determination, dormancy and abscission [18]. The analysis of DEGs in transcriptome of Yuluxiang pear leaves showed a significant effect of drought stress on ethylene, abscisic acid, gibberellin, brassinolide and other plant hormone biosynthesis or signal transduction pathways. Among, the expression of key enzyme genes of ethylene, abscisic acid, and gibberellin biosynthesis was promoted, and these hormones could significantly quicken cell division and leave formation to reduce transpiration rate and improve the water use efficiency of plants during drought stress. However, up-regulation of PHYB activation tagged suppressor 1, a negative regulatory gene involved in the inhibition of brassinolide activity, was also observed, and the reduced brassinolide activity may be conducive to increase soluble sugar and antioxidant enzyme activity, and slow plant cell growth [19-21].

\section{Conclusion}

Present study found that drought stress caused the reduction of nutrients accumulation and inhibition of fruit development. The impairments of the fruit quality of Yuluxiang Pear mainly resulted from the 
weakened antioxidant systematization and increased oxidative stress induced by drought stress. Reduced protective effects against oxidative stress could inhibit the synthesis of photosynthetic pigment, reducing light utilization and photosynthetic productivity. Transcriptome analysis showed that drought stress promoted the biosynthesis of lignin, terpenoids and flavonoids, and carbon fixation process to increase water transportation, and alleviate oxidative stress induced by drought stress. Moreover, the enhanced biosynthesis of plant hormones including ethylene, abscisic acid, and gibberellin could promote cell proliferation and slow young leaves growth.

\section{Methods}

\section{Plant material and growth conditions}

Yuluxaing Pear were investigated in pear germplasm resources yard of Institute of Fruit (Shanxi Academy of Agricultural Science) located in the southwest of Taigu County, Shanxi Province (latitude $37^{\circ} 23^{\prime} 0^{\prime \prime} \mathrm{N}$, longitude $\left.112^{\circ} 32^{\prime} 0^{\prime \prime} \mathrm{E}\right)$. The garden is a warm temperate continental climate with an average annual temperature of $10.6^{\circ} \mathrm{C}$ and sunshine hours of 2300 hours/year, and annual precipitation and evaporation of is about 450 and $1800 \mathrm{~mm} /$ year, respectively.

\section{Test Design}

In present study, the 10-year-old Yuluxiang Pear trees which were not harmed by pests and diseases were selected as the research objects, and the test was carried out from October 21, 2017 to October 21, 2018. The pear tress in control group were given reasonable irrigation as follows: Pear trees were watered for the first time after fertilization in autumn, and the ground was also covered with plastic film to save water in winter. Another two watering was carried out after 15-20 days of flowering when topdressing and before four weeks of harvesting, respectively. For drought treatment groups, there was no water spray in the orchard. The soil moisture content was controlled by the method of weighting and replenishing water after 12 months of plant growth. The soil relative water content of pear trees cultivation in control groups and drought stress groups were $80 \%$ and $30 \%$, respectively.

\section{Detection of Photosynthetic characteristics, chlorophyll content, soluble solids in pear fruit}

Leaves from four different positions around the trees were collected to investigate the effect of drought stress on the photosynthetic characteristics. In the clear and cloudless weather, photosynthetic indexes including net photosynthetic rate (PN), stomatal conductance (GS), intercellular $\mathrm{CO}_{2}$ concentration (Cl) and transpiration rate (TR) were measured by LI-6400 Portable Photosyntometer ((Licor, USA)). Chlorophyll was extracted using $95 \%$ ethanol, and the contents of chlorophyll a, chlorophyll b and carotenoids in the extract were determined according to the method of Li et al. [22]. The soluble solids in pear fruit was measured by the PAL-1 digital display sugar meter

Determination of antioxidant indicators, malondialdehyde (MDA) and osmoregulation substance 
The content of malondialdehyde (MDA) was determined by thiobarbituric acid method (TBA), the activity of superoxide dismutase (SOD) was determined by nitrogen blue tetrazole reduction method, the activity of peroxidase (POD) was determined by guaiacol method, and the activity of catalase (CAT) was determined by ultraviolet absorption method. The content of soluble protein was determined by Coomassie brilliant blue method, and the content of proline was determined by acid ninhydrin method.

\section{Total RNA extraction, cDNA library construction, and deep sequencing}

Total RNA samples (leaves tissues with three repetitions) were isolated following the protocols of Trizol (Invitrogen). RNA content was detected by ND2000 (NanoDrop 2000, Thermo., USA), and RNA samples that had $260 / 280$ ratios above 2.0 were used for subsequent experiments. The sequencing library was constructed by Personal Biotechnology Co., Ltd., and the transcriptome double terminal sequencing was performed by using Illumina hiseq 2500 sequencing platform. Clean reads was obtained after that the low-quality reads were discarded by using the Seq-Prep program, and the clean reads were further de novo assembled by Trinity software [23].

\section{Differentially expressed genes (DEGs) and functional annotation}

The rpkm method (reads per KB per million reads) was used to calculate the expression level of genes. The differential expressed genes (DEGs) were defined as the genes with false discovery rate $P<0.05$ and multiple difference $\geq 2$. Gene function was annotated by using BlastX with an $E$ value less than $10^{-5}$ against NCBI non-redundant (Nr) databases, Swiss Prot, the Protein family (Pfam) database, Cluster of Orthologous Groups databases (COG), Gene Ontology (GO), and the Kyoto Encyclopedia of Genes and Genomes pathway database (KEGG). GO and KEGG pathway enrichment analysis were carried out to further understand the biological functions of DEGs by using the Blast2GO and KOBAS2.0 programs, respectively $[24,25]$.

\section{qRT-PCR analysis}

RNA were isolated from leaves with Trizol, and reverse transcription was performed with MMLV reverse transcriptase (TaKaRa, Dalian, China). qRT-PCR primers were designed with Primer Premier 6 (Supplementary Information Table S1), and their specificity was verified by PCR. qRT-PCR analysis was conducted in triplicate using AceQ® qPCR SYBR® Green Master Mix (Vazyme) with Tubulin as a reference gene by TIB8600 real-time PCR system (Triplex International Biosciences Co., LTD).

\section{Statistical analysis}

Data statistical analysis was carried out with SPSS 17.0 (SPSS, Chicago, IL, USA), and the one-way analysis of variance (ANOVA) and Student-Newman-Kreuls test at $p<0.05$ were used for the statistical analysis between the control groups and drought stress groups.

\section{Abbreviations}


PN: Net photosynthetic rate; GS:Stomatal conductance; Cl:Intercellular $\mathrm{CO}_{2}$ concentration;

TR:Transpiration rate; MDA:Malondialdehyde; TBA:Thiobarbituric acid method; SOD:Superoxide dismutase; POD:Peroxidase (POD); CAT:Catalase; DEGs:Differential expressed genes; Nr:Non-redundant; COG:Cluster of Orthologous Groups databases; GO:Gene Ontology; KEGG:Kyoto Encyclopedia of Genes and Genomes pathway database.

\section{Declarations}

\section{Availability of data and materials}

All data analyzed in this study are included in this published article and supplementary information files.

\section{Ethics approval and consent to participate}

The research project and this study have been approved by an ethics committee from Shanxi agricultural University which found them conform to all national and international guidelines for conservation of endangered species. The plant material used is a common variety which is not endangered.

\section{Consent for publication}

Not applicable.

\section{Competing interests}

The authors declare that they have no known competing financial interests or personal relationships that could have appeared to influence the work reported in this paper.

\section{Funding}

This work was partially supported by the China Agriculture Research System (CARS-28-28), The Doctoral Scientific Fund Project of Shanxi Academy of Agricultural Sciences (YBSJJ1709), The Research Subject of Agricultural Science and Technology Innovation of Shanxi Academy of Agricultural Sciences (YCX2018D2YS14), The Natural Science Foundation of Shanxi Province (201801D121255). There is no role of the funding body in the design of the study and collection, analysis, and interpretation of data and in writing the manuscript.

\section{Authors' contributions}

$\mathrm{HG}, \mathrm{BF}$ and SYdesigned the study and drew up the experimental design. SY, MB, GH implemented the research experiments. SY and XZ analyzed the data. $\mathrm{HG}$ and BF wrote the paper. All authors read and approved the final manuscript. 


\section{Acknowledgments}

Not applicable.

\section{References}

1. Sun P, Wang W. World apple, pear, grape, peach and cherry production, market and trade in 2017/2018. China Fruit Tree. 2018;2:99-108.

2. Tong T. Global. Pear Market Review. China Fruit Industry Information. 2018;35(11):50.

3. Lu H, Geng X. Impact of climate change on Chinese pear production: Based on the data of 28 provinces and municipalities in 1990-2010. J Hunan Agri Uni (Social Sciences). 2014;4:35-40.

4. Bogunovic I, Duralija B, Gadze J. Biostimulant usage for preserving strawberries to climate damages. HortScience. 2015;42(3):132-40.

5. Du B, Haddad SP, Scott WC. Pharmaceutical bioaccumulation by periphyton and snails in an effluentdependent stream during an extreme drought. Chemosphere. 2015;119:927-34.

6. Johnson EJ, Boodram CS. Health, well-being and quality of life of community members displaced after an industrial disaster in Trinidad. J Public Health. 2017;25(1):69-74.

7. Pozzi W, Sheffield J, Stefanski R. Towards Global Drought Early Warning Capability: Expanding international cooperation for the development of a framework for global drought monitoring and forecasting. Bull Am Meteor Soc. 2013;94(6):776-85.

8. Zargar SM, Gupta N, Nazira. M.Impact of drought on photosynthesis: Molecular perspective. Plant Gene. 2017;11:154-9.

9. Flexas J, Medrano H. Drought-inhibition of Photosynthesis in C3 Plants: Stomatal and Non-stomatal Limitations Revisited. Annals of Botany. 200; 89(2): 183-189.

10. Maes WH, Achten WMJ, Reubens B. Plant-water relationships and growth strategies of Jatropha curcas L. seedlings under different levels of drought stress. J Arid Environ. 2009;73(10):877-84.

11. Bunce J. Using New Gas Exchange Methods to Estimate Mesophyll Conductance and Non-stomatal Inhibition of Photosynthesis Caused by Water Deficits. HortScience: a publication of the American Society for Horticultural Science. 2012;47(6):687-90.

12. Ahmed IM, Dai H, Zheng W. Genotypic differences in physiological characteristics in the tolerance to drought and salinity combined stress between Tibetan wild and cultivated barley. Plant Physiol Biochem. 2013;63:49-60.

13. Fang Y, Xiong L. General mechanisms of drought response and their application in drought resistance improvement in plants. Cell Mol Life Sci. 2015;72(4):673.

14. Guo YY, Tian SS, Liu SS. Energy dissipation and antioxidant enzyme system protect photosystem II of sweet sorghum under drought stress. Photosynthetica. 2018;56:861-72.

15. Akula R, Ravishankar GA. Influence of abiotic stress sig- nals on secondary metabolites in plants. Plant Signal Behav. 2011;6(11):1720. 
16. Sharafzadeh S, Zare M. Effect of Drought Stress on Qualitative and Quantitative Characteristics of Some Medicinal Plants from Lamiaceae Family: A Review. Advances in Environ Bio. 2011; 5(8).

17. Hakeem A, Liu Y, Zhang L. Induction of osmotic stress resistance by seed osmo-priming in winter wheat (Triticum aestivum L.) during post-germinative stages. Seed Sci Technol. 2017;45(2):1-14.

18. Lau OS, Deng XW. Plant hormone signaling lightens up: integrators of light and hormones. Curr Opin Plant Biol. 2010;13(5):571-7.

19. Li HB, Wang JN, Chen YJ. Effects of brassinolide on fruit growth and quality of pitaya. J Southern Agri. 2013;44(7):1150-3.

20. Karkar C, Mandavia MK, Mandavia C. Influence of salicylic acid and brassinolide on quality and yield of groundnut kernels. Indian J Agricul Biochem. 2007;20(1):1-5.

21. Fariduddin Q, Khalil RRAE, Mir BA. 24-Epibrassinolide regulates photosynthesis, antioxidant enzyme activities and proline content of Cucumis sativusunder salt and/or copper stress. Environ Monitor Assess. 2013;185(9):7845-56.

22. Li H, Sun Q, Zhao S. Principles and techniques of plant physiological biochemical experimental. Beijing, China. Higher education press. 2000; 184-185.

23. Grabherr MG, Haas BJ, Yassour M. Full-length transcriptome assembly from RNA-Seq data without a reference genome. Nat Biotech. 2011;29(7):644-52.

24. Conesa A, Gotz S. Blast2GO: A comprehensive suite for functional analysis in plant genomics. Int $\mathrm{J}$ plant genomics. 2008; 619832.

25. Kanehisa M, Araki M, Goto S, Hattori M, Hirakawam M. KEGG for linking genomes to life and the environment. Nucleic Acids research. 2008;36:D480-4.

\section{Tables}

Table 1 Effects of drought stress on fruit quality of Yuluxiang Pear

\begin{tabular}{|lll|}
\hline Groups & Fruit soluble solids content \% & fruit weight/g \\
\hline Drought stress & $12.0 \pm 0.96^{\star}$ & $235 \pm 18.36^{\star}$ \\
\hline Control & $13.8 \pm 0.82$ & $345 \pm 15.58$ \\
\hline
\end{tabular}

Table 2 Effects of drought stress on photosynthetic characteristics in leaves of Yuluxiang Pear 


\begin{tabular}{|c|c|c|c|c|}
\hline \multirow[t]{2}{*}{ Groups } & Pn & $\mathrm{Tr}$ & $\mathrm{Ci}$ & Gs \\
\hline & Dpmol$\cdot \mathrm{m}-2 \cdot \mathrm{s}-10$ & 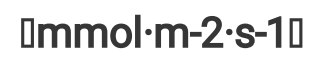 & [umol/moln & Immol-m-2·s-10 \\
\hline Drought stress & $8.33 \pm 0.26^{\star}$ & $3.61 \pm 0.26^{\star}$ & $233.95 \pm 1.23^{*}$ & $120.36 \pm 1.86^{\star}$ \\
\hline Control & $14.65 \pm 0.85$ & $5.61 \pm 0.36$ & $287.26 \pm 1.57$ & $151.26 \pm 3.25$ \\
\hline
\end{tabular}

Table 3 Effects of drought stress on photosynthetic pigment content in leaves of Yuluxiang Pear

\begin{tabular}{|llllll|}
\hline Groups & $\begin{array}{l}\text { Chlorophyll a } \\
(\mathbf{m g} / \mathbf{g})\end{array}$ & $\begin{array}{l}\text { Chlorophyll b } \\
(\mathbf{m g} / \mathbf{g})\end{array}$ & $\begin{array}{l}\text { Chlorophyll a+b } \\
(\mathbf{m g} / \mathbf{g})\end{array}$ & $\begin{array}{l}\text { Chlorophyll } \\
\mathbf{a} / \mathbf{b}\end{array}$ & $\begin{array}{l}\text { Carotenoid } \\
\mathbf{( m g / g})\end{array}$ \\
\hline $\begin{array}{l}\text { Drought } \\
\text { stress }\end{array}$ & $1.73 \pm 0.15^{\star}$ & $1.74 \pm 0.05^{\star}$ & $3.74 \pm 0.13^{*}$ & $0.99 \pm 0.05^{\star}$ & $14.22 \pm 0.86^{\star}$ \\
\hline Control & $2.23 \pm 0.23$ & $2.65 \pm 0.13$ & $4.88 \pm 0.21$ & $0.84 \pm 0.08$ & $17.55 \pm 0.73$ \\
\hline
\end{tabular}

Table 4 Effects of drought stress on MDA content and antioxidant enzyme activity in leaves of Yuluxiang Pear

\begin{tabular}{|lllll|}
\hline Groups & $\begin{array}{l}\text { MDA content } \\
(\mathbf{U m o l} / \mathbf{g})\end{array}$ & $\begin{array}{l}\text { SOD activity } \\
(\mathbf{U} / \mathbf{g})\end{array}$ & $\begin{array}{l}\text { POD activity } \\
(\mathbf{U} / \mathbf{g})\end{array}$ & $\begin{array}{l}\text { CAT activity } \\
(\mathbf{U} / \mathbf{g})\end{array}$ \\
\hline Drought stress & $1.83 \pm 0.25^{\star}$ & $5.9 \pm 0.29^{\star}$ & $8.3 \pm 0.35^{\star}$ & $4.3 \pm 0.41^{\star}$ \\
\hline Control & $1.66 \pm 0.16$ & $8.3 \pm 0.24$ & $9.4 \pm 0.52$ & $6.8 \pm 0.34$ \\
\hline
\end{tabular}

Table 5 Effects of drought stress on osmoregulation substance content in leaves of Yuluxiang Pear

\begin{tabular}{|lll|}
\hline Groups & Soluble protein content $(\mathrm{mg} / \mathrm{g})$ & $\begin{array}{l}\text { proline content } \\
(\mathrm{mg} / \mathrm{g})\end{array}$ \\
\hline Drought stress & $10.21 \pm 0.89 *$ & $18.58 \pm 0.95^{\star}$ \\
\hline Control & $14.59 \pm 0.16$ & $27.53 \pm 0.49$ \\
\hline
\end{tabular}

Table 6 PacBio libraries and sequencing results. 


\begin{tabular}{|lllllll|}
\hline Sample & Reads No. & Bases (bp) & Q30 (bp) & N (\%) & $\begin{array}{l}\text { Q20 } \\
(\%)\end{array}$ & $\begin{array}{l}\text { Q30 } \\
(\%)\end{array}$ \\
\hline Control groups & 204157258 & 30827745958 & 28252595080 & 0.0043574 & 96.316 & 91.644 \\
\hline $\begin{array}{l}\text { Drought stress } \\
\text { groups }\end{array}$ & 209344612 & 31611036412 & 24352878562 & 0.0044588 & 96.542 & 92.066 \\
\hline
\end{tabular}

Note: Reads No.: total number of reads; Bases (bp): total number of bases; Q30 (bp): the total number of bases whose recognition accuracy is more than $99.9 \% ; \mathrm{N}(\%)$ : percentage of fuzzy bases; Q20 (\%): the percentage of bases whose recognition accuracy is more than 99\%; Q30 (\%): percentage of bases with accuracy over $99.9 \%$.

Table 7 Statistics after data filtering

\begin{tabular}{|lllll|}
\hline Sample & Clean Reads No. & Clean Data (bp) & Clean Reads \% & Clean Data \% \\
\hline Control groups & 189653068 & 28637613268 & 92.888 & 92.888 \\
\hline Drought stress groups & 194811350 & 29416513850 & 93.05 & 93.05 \\
\hline
\end{tabular}

Note: Clean reads No: number of high-quality sequence reads; Clean data (BP): base number of high quality sequence; Clean reads \%: the percentage of high-quality sequence reads in sequencing reads; Clean data \%: the percentage of high-quality sequence bases to sequence bases.

Table 8 Summary of database matches for the Yuluxiang Pear

\begin{tabular}{|lll|}
\hline Anno Database & Annotated Number & Percentage \\
\hline GO & 9534 & 35.92 \\
\hline KEGG & 11589 & 43.67 \\
\hline EC & 25948 & 97.78 \\
\hline eggNOG & 21774 & 82.05 \\
\hline
\end{tabular}

Table 9. Summary of major deferentially expressed genes in leaves of Yuluxiang Pear under drought stress by gene ontology classification 


\begin{tabular}{|c|c|c|c|c|c|c|c|}
\hline Category & GO.ID & Term & DEG & UP & DOWN & $\begin{array}{l}P \\
\text { value }\end{array}$ & FDR \\
\hline $\begin{array}{l}\text { Molecular } \\
\text { Function }\end{array}$ & GO:0003674 & Molecular function & 352 & 189 & 163 & 0.0003 & 0.0092 \\
\hline $\begin{array}{l}\text { Biological } \\
\text { Process }\end{array}$ & GO:0008150 & Biological process & 290 & 164 & 126 & 0.0005 & 0.0117 \\
\hline $\begin{array}{l}\text { Molecular } \\
\text { Function }\end{array}$ & GO:0005488 & binding & 238 & 119 & 119 & 0.0009 & 0.0189 \\
\hline $\begin{array}{l}\text { Molecular } \\
\text { Function }\end{array}$ & G0:0003824 & catalytic activity & 217 & 119 & 98 & 0.0018 & 0.0330 \\
\hline $\begin{array}{l}\text { Cellular } \\
\text { Component }\end{array}$ & GO:0005634 & nucleus & 61 & 19 & 42 & 0.0001 & 0.0021 \\
\hline $\begin{array}{l}\text { Molecular } \\
\text { Function }\end{array}$ & GO:0003677 & DNA binding & 60 & 26 & 34 & 0.0000 & 0.0009 \\
\hline $\begin{array}{l}\text { Molecular } \\
\text { Function }\end{array}$ & GO:0016491 & $\begin{array}{l}\text { Oxidoreductase } \\
\text { activity }\end{array}$ & 59 & 40 & 19 & 0.0002 & 0.0081 \\
\hline $\begin{array}{l}\text { Biological } \\
\text { Process }\end{array}$ & GO:0055114 & $\begin{array}{l}\text { Oxidation-reduction } \\
\text { process }\end{array}$ & 55 & 39 & 16 & 0.0002 & 0.0061 \\
\hline $\begin{array}{l}\text { Molecular } \\
\text { Function }\end{array}$ & G0:0005515 & Protein binding & 47 & 12 & 35 & 0.0000 & 0.0002 \\
\hline $\begin{array}{l}\text { Cellular } \\
\text { Component }\end{array}$ & G0:0043228 & $\begin{array}{l}\text { Non-membrane- } \\
\text { bounded organelle }\end{array}$ & 36 & 3 & 33 & 0.0001 & 0.0030 \\
\hline
\end{tabular}

Table 10 Summary of deferentially expressed genes in leaves of Yuluxiang Pear under drought stress by KEGG classification 


\begin{tabular}{|llllll|}
\hline $\begin{array}{l}\text { Pathway } \\
\text { ID }\end{array}$ & Pathway & $\begin{array}{l}\text { DEG } \\
\text { number }\end{array}$ & $\begin{array}{l}\text { UP } \\
\text { regulated }\end{array}$ & $\begin{array}{l}\text { DOWN } \\
\text { regulated }\end{array}$ & $P$ value \\
\hline ko00940 & Phenylpropanoid biosynthesis & 17 & 15 & 2 & 0.00796474 \\
\hline ko00270 & $\begin{array}{l}\text { Cysteine and methionine } \\
\text { metabolism }\end{array}$ & 12 & 5 & 7 & 0.001795144 \\
\hline ko00941 & Flavonoid biosynthesis & 8 & 8 & 0 & 0.001456809 \\
\hline ko00904 & Diterpenoid biosynthesis & 6 & 4 & 2 & 0.001805978 \\
\hline ko00906 & Carotenoid biosynthesis & 6 & 6 & 0 & 0.005512177 \\
\hline ko00902 & Monoterpenoid biosynthesis & 5 & 5 & 0 & 0.000279212 \\
\hline ko00909 & $\begin{array}{l}\text { Sesquiterpenoid and } \\
\text { triterpenoid biosynthesis }\end{array}$ & 4 & 3 & 1 & 0.019830348 \\
\hline ko00905 & Brassinosteroid biosynthesis & 3 & 2 & 1 & 0.042461752 \\
\hline
\end{tabular}

Table 11 Drought stress up-regulated key genes involved in secondary metabolism in leaves of Yuluxiang pear

\begin{tabular}{|c|c|c|}
\hline Pathways & Genes & Ratios \\
\hline \multirow[t]{6}{*}{ Phenylpropanoid biosynthesis } & Peroxidase & $21.47^{\star}$ \\
\hline & Caffeic acid 3-0-methyltransferase & $19.24^{\star}$ \\
\hline & Shikimate O-hydroxycinnamoyltransferase & $11.02^{\star}$ \\
\hline & Cinnamyl-alcohol dehydrogenase & $16.54^{\star}$ \\
\hline & Cinnamoyl-CoA reductase & $10.07^{*}$ \\
\hline & Ferulate-5-hydroxylase & $4.41^{*}$ \\
\hline \multirow[t]{2}{*}{ Cysteine and methionine metabolism } & Methionine-gamma-lyase & $4.81^{*}$ \\
\hline & Cysteine synthase & $4.60 *$ \\
\hline Glycometabolism & Malate dehydrogenase & $2.37 *$ \\
\hline \multirow[t]{2}{*}{ Monoterpenoid biosynthesis } & Neomenthol dehydrogenase & $28.38^{*}$ \\
\hline & (3S)-linalool synthase & $15.11^{\star}$ \\
\hline $\begin{array}{l}\text { Sesquiterpenoid and triterpenoid } \\
\text { biosynthesis }\end{array}$ & Lupeol synthase 2 & $13.43^{*}$ \\
\hline
\end{tabular}


* Significant effect of drought stress on gene mRNA expression is given as induction (>1) or repression $(<1)$ factor. The $p$ levels are indicated as $p<0.05$.

Table 12 Drought stress regulated key genes involved in plant hormones biosynthesis and signal transduction in leaves of Yuluxiang pear

\begin{tabular}{|lll|}
\hline Functions & Genes & Ratios \\
\hline Ethylene synthesis & 1-aminocyclopropane-1-carboxylate synthase & 2.90 \\
\cline { 2 - 3 } & Aminocyclopropanecarboxylate oxidase & 4.75 \\
\hline Gibberellins biosynthesis & Gibberellin 2beta-dioxygenase & 73.22 \\
\hline Abscisic acid biosynthesis & 9-cis-epoxycarotenoid dioxygenase & 16.67 \\
\hline Brassinosteroid biosynthesis & PHYB activation tagged suppressor 1 & 6.50 \\
\hline
\end{tabular}

\section{Figures}




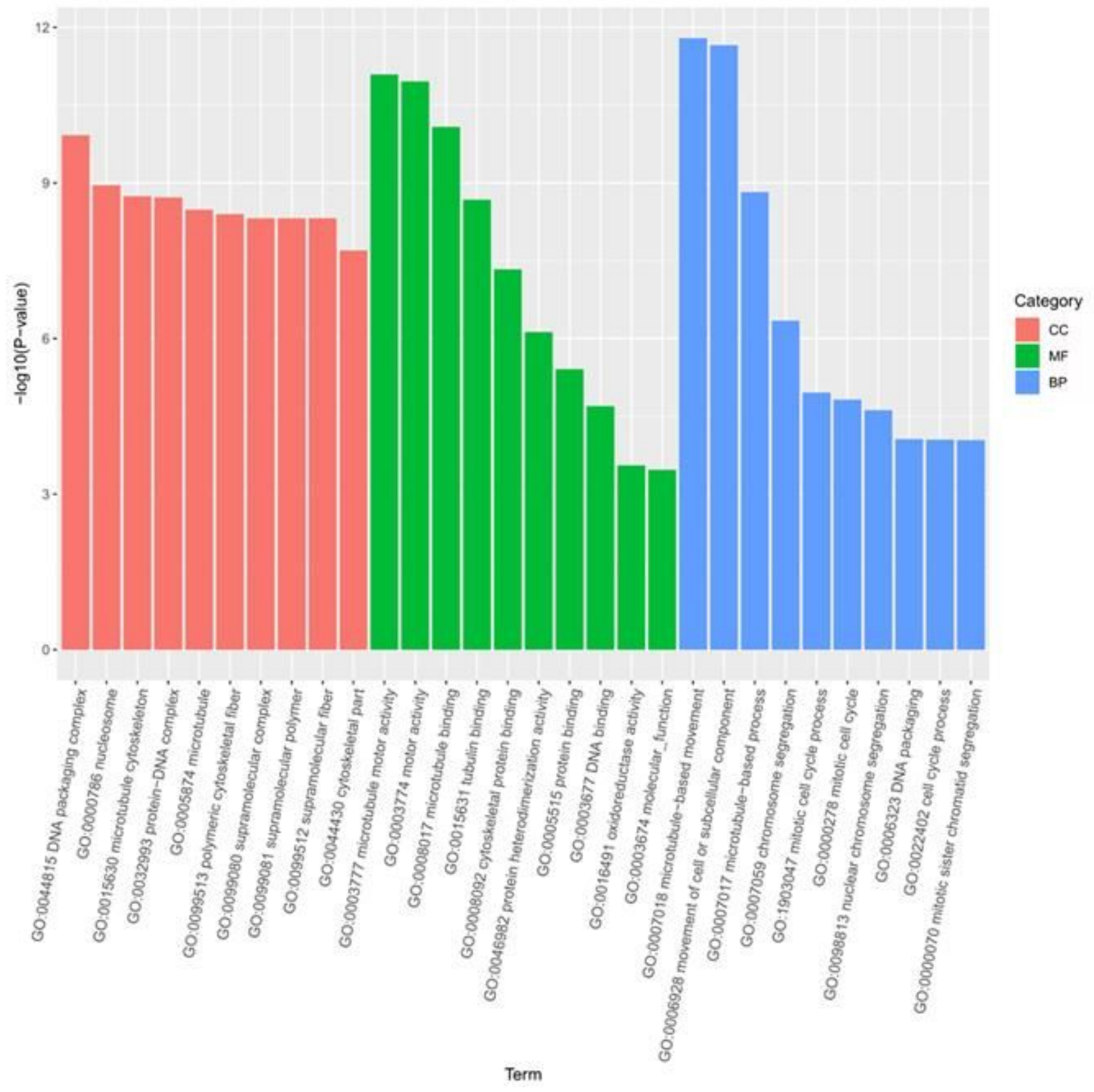

\section{Figure 1}

Go categories of drought stress regulated DEGs in leaves of Yuluxiang Pear Note: Gene ontology was summarized as three main categories: cellular component (CC, left panel), molecular function (MF, middle panel), and biological process (BP, right panel). The percentage (left Y-axis) and number (right Y-axis) of genes were also showed.

\section{Supplementary Files}

This is a list of supplementary files associated with this preprint. Click to download. 
- Additionalfile1.doc

Page 18/18 